\title{
AUGMENTED REALITY SEBAGAI MEDIA PENGENALAN DAN PROMOSI UNIVERSITAS NASIONAL
}

\author{
Danang Aji Pangestu, Iskandar Fitri, Fauziah \\ Program Studi Informatika, Universitas Nasional \\ Jl. Sawo Manila, RT.14/RW.3, Ps. Minggu, Kec. Ps. Minggu, Kota Jakarta Selatan, Daerah Khusus Ibukota \\ Jakarta 12520 \\ nangjipang@gmail.com, iskandar.fitri@civitas.unas.ac.id, fauziah@civitas.unas.ac.id
}

\begin{abstract}
Universitas Nasional is the second oldest private university in Indonesia and the oldest private university in Jakarta. But there are still many people who do not know the information about the Universitas Nasional, for that we need an application as a media introduction to the Universitas Nasional. This study utilizes augmented reality technology as an application to introduce and promote the Universitas Nasional in 3D with the Marker Based Tracking method, which utilizes the logo of the Universitas Nasional as a marker for scanning to bring up objects. The system development method in this study uses the MDLC (Multimedia Development Life Cycle) method which consists of six stages, namely concept, design, material collecting, assembly, testing, distribution. With the application of ARNAS (Augmented Reality Universitas Nasional) can be a media introduction and promotion at the Universitas Nasional. The results of the study resulted in an application in the form of displaying miniature Universitas Nasional buildings in $3 D$, a brief history, faculties, and room names for each block, as well as how to use the application. The ARNAS application can run well on the Android operating system.
\end{abstract}

Keywords - Augmented Reality, Marker Based Tracking, MDLC, Android.

\begin{abstract}
Abstrak - Univeritas Nasional merupakan Universitas swasta tertua kedua di Indonesia, dan Universitas swasta tertua di Jakarta. Namun masih banyak orang yang belum mengetahui informasi tentang Universitas Nasional, untuk itu dibutuhkan sebuah aplikasi sebagai media pengenalan Universitas Nasional. Penelitian ini memanfaatkan teknologi augmented reality sebagai aplikasi pengenalan dan promosi Universitas Nasional secara 3D dengan metode Marker Based Tracking, dimana memanfaatkan logo dari Universitas Nasional sebagai marker untuk dilakukan scanning agar memunculkan objek. Metode pembangunan sistem pada penelitian ini menggunakan metode MDLC (Multimedia Development Life Cycle) yang terdiri dari enam tahap, yaitu konsep (concept), desain (design), pengumpulan bahan (material collecting), perakitan (assembly), pengujian (testing), distribusi (distribution). Dengan adanya aplikasi ARNAS (Augmented Reality Universitas Nasional) dapat menjadi media pengenalan sekaligus media promosi pada Universitas Nasional. Hasil penelitian mengasilkan aplikasi berupa menampilkan miniatur gedung Universitas Nasional secara 3D, sejarah singkat, fakultas, dan nama ruangan setiap blok, serta cara pemakaian aplikasi. Aplikasi ARNAS dapat berjalan dengan baik pada sistem operasi android.
\end{abstract}

Kata kunci - Augmented Reality, Marker Based Tracking, MDLC, Android.

\section{PENDAHULUAN}

Universitas Nasional merupakan salah satu Universitas tertua di Indonesia dan Jakarta. Didirikan pada tahun 1949 membuat Universitas Nasional dikenal oleh masyarakat. Namun tak sedikit orang yang belum mengetahui Universitas Nasional dan informasi mengenai Universitas Nasional. Pengenalan terhadap lingkungan kampus menjadi sangat penting sebagai sebuah media memperkenalkan Universitas Nasional.

Ada banyak cara dalam upaya pengenalan yang digunakan dalam sebuah informasi pengenalan kampus, salah satunya dengan memanfaatkan teknologi augmented reality yang memungkinkan menampilkan objek 3D yang seolah-olah nyata.

Pada penelitian terdahulu dilakukan penelitian terkait metode marker based tracking sebagai pengenalan kampus dengan judul "Implementasi Augmented Reality Sebagai Media Pengenalan
Promosi Universitas Nurtanio Bandung Menggunakan Unity 3d" yang mengimplementasikan Unity 3D engine untuk keperluan promosi Universitas Nurtanio Bandung dan mengimplementasikan aplikasi augmented reality untuk menampilkan gambar 3D pada brosur yang telah dipasang marker dengan view berbasis webcam [1].

Penelitian terkait juga dilakukan dengan judul "Penerapan Teknologi Augmented Reality Sebagai Media Pengenalan Kampus Berbasis Android Dengan Menggunakan Metode Multimedia Development Life Cycle". Seperti Universitas pada umumnya, media pengenalan kampus di Universitas Majalengka sendiri masih menggunakan cara konvensional. Hal itu terlihat dari beberapa baligho dan brosur yang tersebar di beberapa titik kota Majalengka. Akibatnya, daya tarik untuk para peminat Universitas Majalengka menjadi berkurang dikarenakan informasi mengenai beberapa fasilitas yang terdapat di Universitas Majalengka 
kurang tergambarkan dengan jelas untuk para calon mahasiswa baru. Maka dibutuhkan suatu media pengenalan kampus bagi calon mahasiswa baru yang lebih kreatif dan menarik yang dapat memberikan gambaran visualisasi 3D mengenai fasilitas-fasilitas yang terdapat dalam kampus tersebut [2].

Penelitian serupa terkait marker based tracking juga dilakukan dengan judul "Media Pendukung Pengenalan Gedung Fakultas Teknik Unwahas Dengan Augmented Reality Berbasis Android" yang digunakan sebagai media pendukung pengenalan gedung fakultas teknik unwahas untuk masyarakat khususnya pelajar sekolah menengah atas yang ingin melanjutkan pendidikan di fakultas teknik unwahas . Aplikasi juga untuk menarik minat masyarakat terhadap fakultas teknik unwahas [3].

Metode marker based tracking juga digunakan sebagai media pengenalan kampus pada penelitian yang berjudul "Augmented Reality Media Pendukung Pengenalan Kampus Universitas Wahid Hasyim Semarang" yang dapat digunakan sebagai media pendukung pengenalan kampus Universitas Wahid Hasyim Semarang dan diterapkan pada perangkat android dengan baik. Aplikasi Augmented Reality ini telah meliputi beberapa pengujian, meliputi pengujian aplikasi dengan menggunakan pengujian black box, pengujian pada perangkat, dan pengujian pendeteksian marker [4].

Pengenalan kampus menggunakan metode marker based tracking juga dilakukan pada penelitian "Penerapan Augmented Reality sebagai Media Pengenalan Kampus Politeknik Negeri Ujung Pandang" bahwa pembangunan aplikasi dengan memanfaatkan teknologi augmented reality berhasil dan sesuai dengan perancangan, serta dapat digunakan dan berjalan dengan baik dalam hal pengimplentasian pengenalan Kampus PNUP yang lebih menarik karena dapat melihat secara kesluruhan bangunan kampus dan juga beberapa rungan yang ada dalam Gedung tersebut [5].

Dari beberapa penelitian yang sebelumnya telah dikemukakan, maka penulis melakukan penelitian dan memaparkan tahap yang dilakukan pada pembuatan aplikasi ARNAS (Augmented Reality Universitas Nasional).

Augmented reality dipilih karena dapat menampilkan objek baik 3D maupun 2D menggunakan perangkat mobile yang hanya menggunakan marker sebagai penanda objek agar objek dapat muncul. Pembuatan aplikasi ARNAS dibuat menggunakan software Unity 3D dan Vuforia sebagai SDK (software development kit).

\section{A. Augmented Reality}

Augmented reality tidak lain adalah informasi digital yang terletak diatas objek dunia nyata dimana pengguna dapat beriteraksi dengan konten virtual didunia nyata yang dapat membedakan antara dunia nyata dan virtual. Augmented reality digambarkan sebagai kemampuan untuk mengintegrasikan grafik dan konten multimedia lainnya dengan mulus dan dinamis dengan tampilan kamera langsung di pc atau smartphone. Scane dapat dilihat pada gambar device berupa kamera ponsel atau kamera video [6].

\section{B. Android Platform}

Android merupakan sebuah sistem operasi yang berbasis Linux untuk telepon seluler seperti telepon pintar dan komputer tablet. Android menyediakan platform terbuka bagi para pengembang untuk menciptakan aplikasi mereka sendiri untuk digunakan oleh bermacam peranti bergerak. Android adalah sistem operasi yang digunakan di smartphone dan juga tablet PC. Fungsinya sama seperti sistem operasi Symbian di Nokia, iOS di Apple dan BlackBerry OS. Android tidak terikat pada satu merek Handphone saja, beberapa vendor terkenal yang sudah memakai Android antara lain Samsung, Sony Ericsson, HTC, Nexus, Motorolla, dan lain-lain [7].

\section{Marker}

Marker merupakan gambar yang dirancang, yang akan digunakan sebagai gambar untuk dikenali oleh webcam, sehingga dapat membantu menampilkan aplikasi selanjutnya pada perangkat android untuk menampilkan informasi dari aplikasi yang dibangun [8].

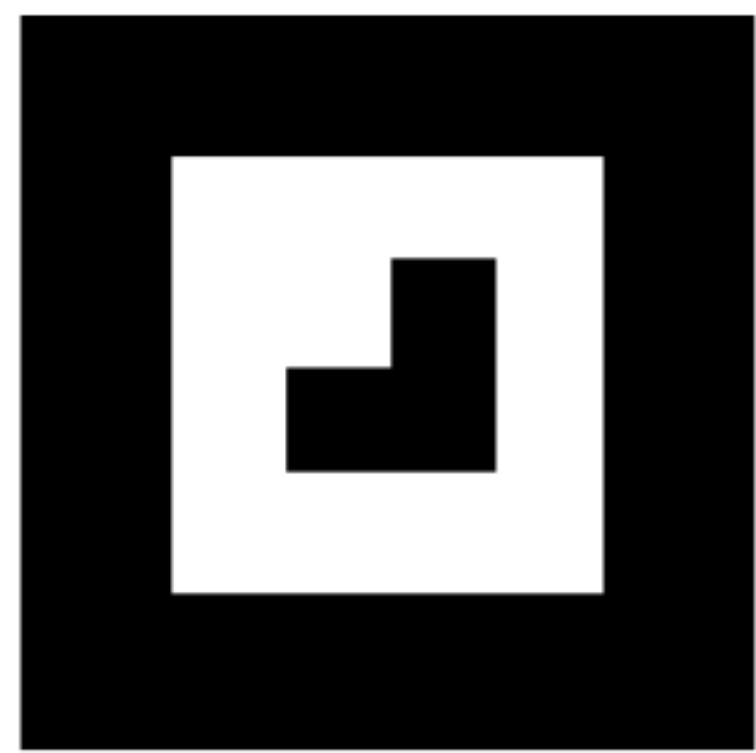

Gambar 1. Contoh dari Marker

Pada gambar 1 merupakan contoh marker yang dapat digunakan untuk memunculkan objek pada augmented reality. Sedangkan pada penelitian ini menggunakan objek logo dari Universitas Nasional sebagai marker. Berikut merupakan marker yang digunakan pada penelitian. 


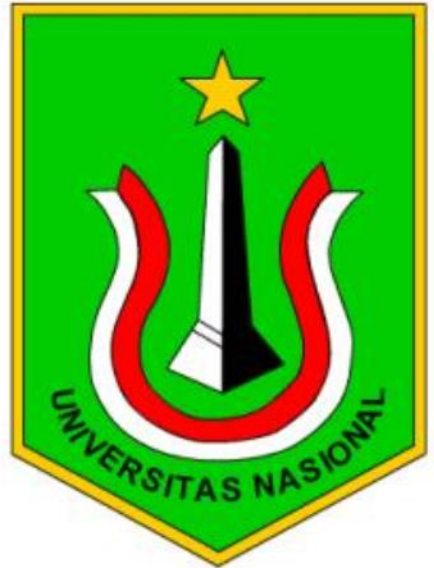

Gambar 2. Marker Aplikasi ARNAS

Titik koordinat virtual pada marker berfungsi untuk menentukan posisi dari objek virtual yang akan ditambahkan pada lingkungan nyata. Posisi dari objek virtual akan terletak tegak lurus dengan marker. Objek virtual akan berdiri segaris dengan sumbu $\mathrm{Z}$ serta tegak lurus terhadap sumbu X (kanan atau kiri) dan sumbu Y (depan atau belakang) dari koordinat virtualmarker. Ilustrasi [9].

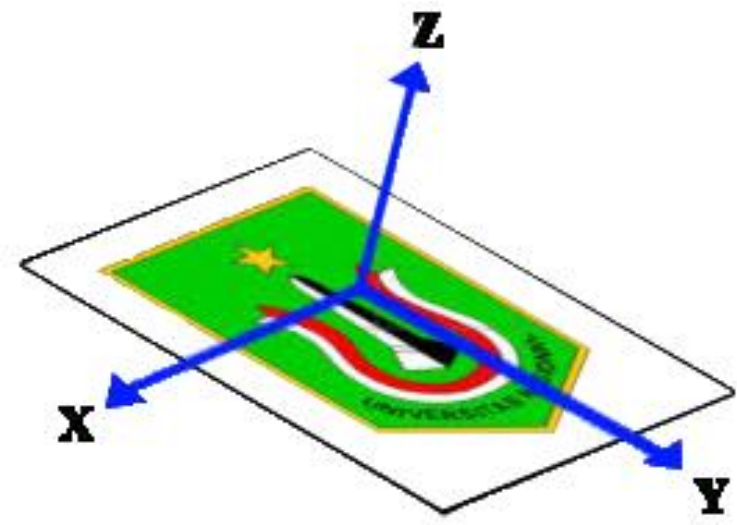

Gambar 3. Titik Koordinat Marker

\section{Unity $3 D$}

Unity3D merupakan sebuah media pengembangan game baik 3D dan 2D. Karena unity mendukung banyak platform, game dapat dikembangkan di berbagai platform seperti iOS, Android, dan Blackberry [10]. Pada penelitian ini, perangkat yang digunakan adalah platform Android.

\section{E. Vuforia}

Vuforia adalah sebuah AR SDK untuk perangkat genggam, seperti ponsel cerdas dan tablet. Vuforia menempatkan objek 2D dan 3D secara real-time. Vuforia bergantung pada teknologi computer vision untuk mengenali, mendeteksi, dan melacak objek yang ditangkap oleh kamera secara real-time [11].

\section{METODE PENELITIAN}

Metode yang digunakan pada penelitian dalam pembangunan aplikasi ARNAS menggunakan dua metode, yaitu metode pada augmented reality yang menggunakan metode marker based tracking, dan metode pada pengembangan software yang menggunakan metode MDLC (Multimedia Development Life Cycle).

\section{A. Marker Based Tracking}

Marker based tracking merupakan AR yang menggunakan marker atau penanda objek 2D yang memiliki suatu pola yang akan dibaca komputer melalui media webcam atau kamera yang tersambung dengan komputer. Marker based tracking biasanya merupakan ilustrasi hitam dan putih persegi dengan batas hitam tebal dan latar belakang putih [12].

\section{B. Multimedia Development Life Cycle}

Pada pembuatan aplikasi ARNAS digunakan metode development software yaitu MDLC (Multimedia Development Live Cycle) yang terdiri dari enam tahapan, antara lain konsep (concept), desain (design), pengumpulan bahan (material collecting), perakitan (assembly), pengujian (testing), distribusi (distribution).

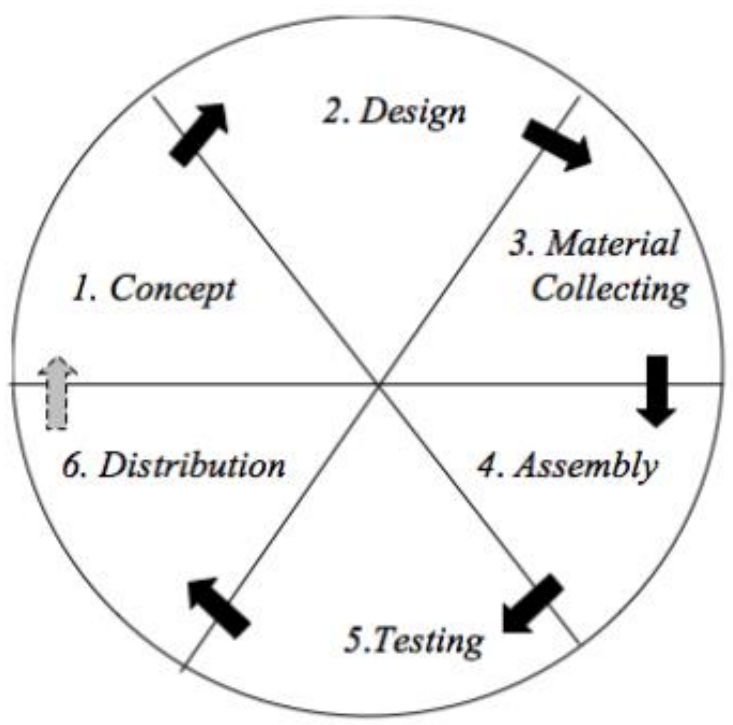

Gambar 4. Metode MDLC

Berikut merupakan tahapan-tahapan penelitian menggunakan metode MDLC.

1). Konsep (Concept)

Konsep sendiri merupakan menentukan tujuan, ide, serta gagasan untuk mudah dipahami. Tujuan dari penelitian adalah menggunakan teknologi augmented reality sebagai media pengenalan dan promosi Universitas Nasional. 
Ide penelitian didapat melalui tahapan pengumpulan studi literatur yang dilakukan terkait penelitian yang dilakukan.

Penelitian menghasilkan sebuah aplikasi ARNAS (Augmented Reality Universitas Nasional) yang telah melalui perencanaan agar mudah dipahami ketika digunakan. Perencanaan tersebut yaitu metode yang digunakan, objek 3D berupa bangunan Universitas Nasional, menentukan marker yang akan digunakan untuk memunculkan objek.

2). Desain (Design)

Desain merupakan rancangan terkait penelitian yang dilakukan. Rancangan tersebut sudah melalui tahap konsep atau tahap sebelumnya. Desain tersebut antara lain pembuatan alur penggunaan aplikasi melalui flowchart, navigasi, dan Rancangan Antar Muka pengguna dari aplikasi.

3). Pengumpulan Bahan (material collecting)

Tahap pengumpulan bahan mengenai apa saja yang dibutuhkan. Bahan tersebut antara lain logo dari Universitas Nasional yang digunakan sebagai marker, foto, dan kebutuhan sistem yang mencakup hardware dan software.

4). Perakitan (assembly)

Tahap pembuatan objek yang didasarkan dari tahap dasain, dan bagian alir. Tahap ini menggunakan sebuah software game enggine yaitu Unity3D dan sebuah SDK yaitu Vuforia.

5). Pengujian (testing)

Setelah aplikasi selesai, dilakukan tahap pengujian.

Tahap pengujian antara lain memeriksa aplikasi ARNAS yang dibuat sudah sesuai, memeriksa GUI (Graphic User Interface) pada aplikasi, memastikan tidak adanya bug pada aplikasi.

6). Distribusi (distribution)

Merupakan tahap penyimpanan aplikasi pada sebuah media penyimpanan. Pada tahap ini juga dilakukan sebuah evaluasi terkait aplikasi. Jika ada hal yang dievaluasi, maka tahap penelitian akan kembali pada tahap konsep (concept).

\section{Kebutuhan Sistem}

Demi mendukung kebutuhan sebagai penunjang pembuatan aplikasi ARNAS, tentunya memerlukan perangkat yang memadai, baik dari sisi software (perangkat lunak) dan juga hardware (perangkat keras). Untuk itu perlu adanya dukungan pada perangkat hardware dan software.

Tabel 1. Spesifikasi hardware yang digunakan

\begin{tabular}{|l|l|}
\hline \multicolumn{1}{|c|}{ Perangkat } & \multicolumn{1}{|c|}{ Spesifikasi } \\
\hline Prosesor & $\begin{array}{l}\text { Intel } \mathbb{C} \text { Core } \\
\text { TM i5-3470 CPU }\end{array}$ \\
& @3.20GHz (4 CPUs) \\
\hline RAM & $8 \mathrm{~GB}$ \\
\hline Hardisk & $500 \mathrm{~GB}$ \\
\hline
\end{tabular}

. Tabel 2. Spesifikasi software yang digunakan

\begin{tabular}{|l|l|}
\hline \multicolumn{1}{|c|}{ Perangkat } & \multicolumn{1}{|c|}{ Kegunaan } \\
\hline $\begin{array}{l}\text { Sistem Operasi Microsoft } \\
\text { bit }\end{array}$ & $\begin{array}{l}\text { Sistem operasi yang digunakan } \\
\text { peneliti dalam membangun } \\
\text { aplikasi }\end{array}$ \\
\hline Unity 3D 2017.3.0f3 64-bit & $\begin{array}{l}\text { Merupakan game engine yang } \\
\text { digunakan untuk pembuatan } \\
\text { aplikasi Selain disistem }\end{array}$ \\
operasi windows, software \\
unity dapat dijalankan pada \\
sistem operasi lain seperti linux \\
dan mac os.
\end{tabular}

\section{HASIL DAN PEMBAHASAN}

\section{A. Flowchart}

Flowchart digunakan sebagai penggambaran penggunaan aplikasi yang dijabarkan melalui diagram alir. Berikut merupakan flowchart pada aplikasi ARNAS.

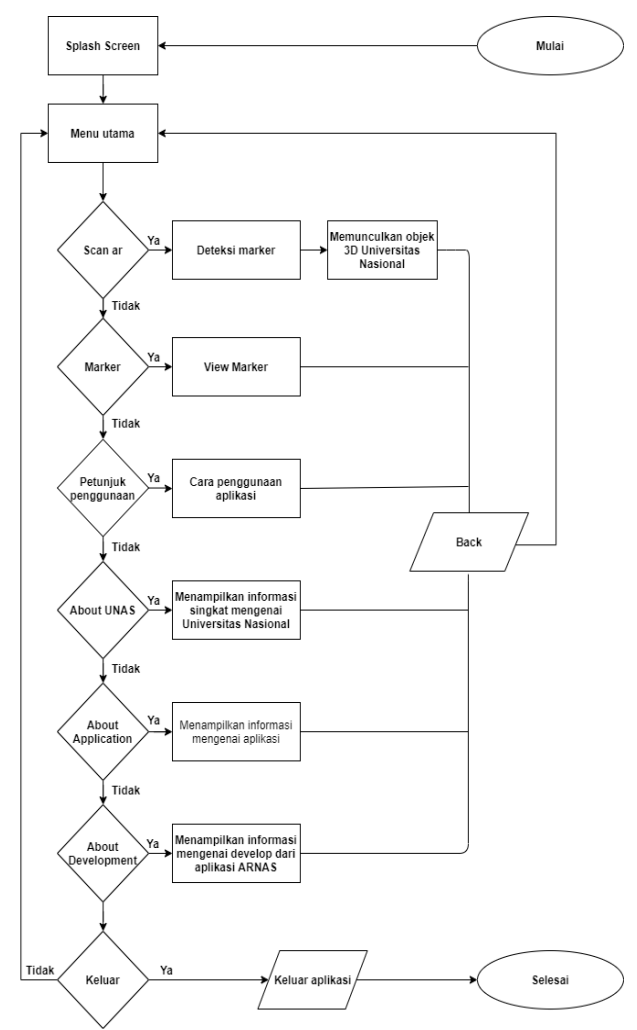

Gambar 5. Flowchart Dari Aplikasi ARNAS 
B. Implementasi GUI (Graphic User Interface)

Dalam perancangan aplikasi, dilakukan membuat interface. Berikut merupakan interface pada aplikasi ARNAS.

1). Splashscreen

Tampilan awal splashcreen pada aplikasi ARNAS.

Tampilan splashscreen menampilkan logo dari apliasi ARNAS.

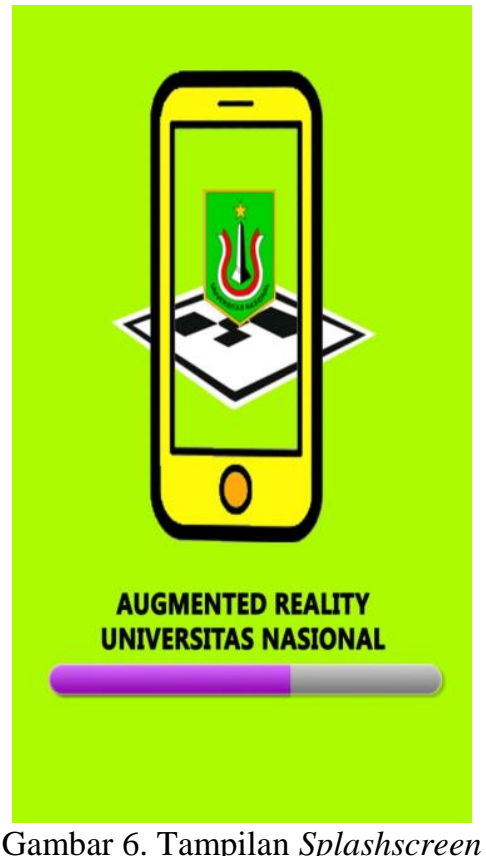

2). Main Menu

Tampilan menu utama pada aplikasi ARNAS. Terdapat 6 pilihan, yaitu start camera, view marker, how to use, about unas, about application, about development.
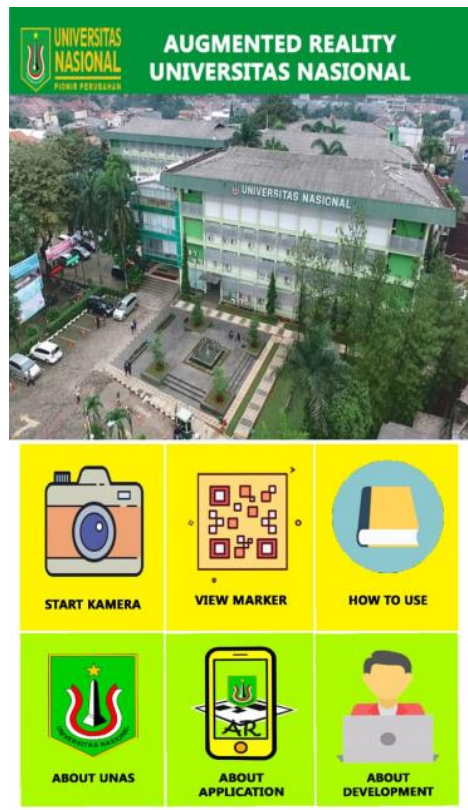

Gambar 7. Tampilan Main Menu

\section{3). Start Camera}

Pada pilihan Start Camera akan menampilkan sebuah tampilan yang akan menampilkan objek 3D Universitas Nasional dari marker yang terditeksi.

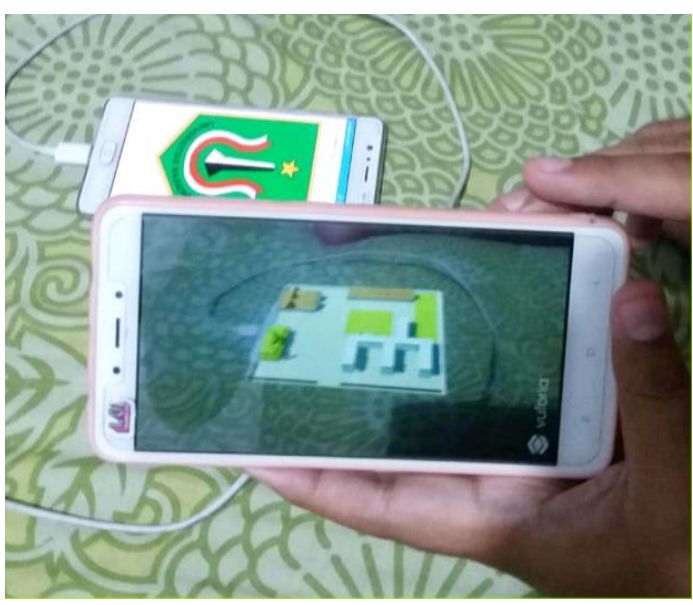

Gambar 8. Tampilan Start Camera

4). View Marker

Pada view marker akan menampilkan marker yang dapat digunakan agar objek 3D dapat terlihat. Marker yang digunakan merupakan logo dari Universitas Nasional.

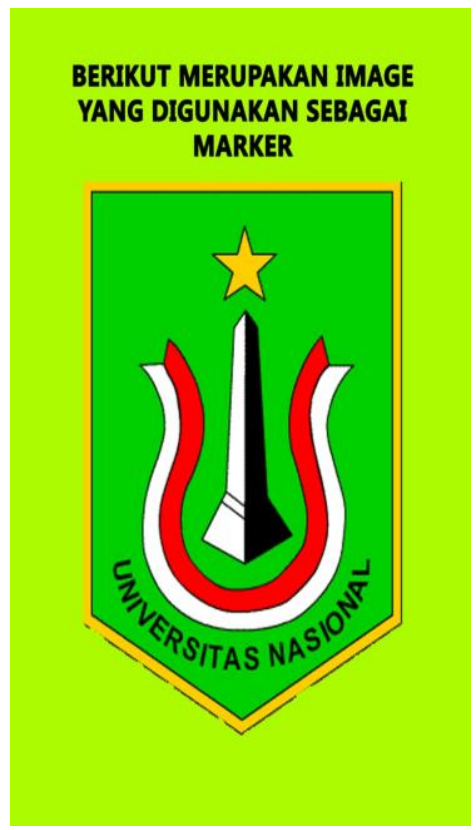

Gambar 9. View Marker

5). How To Use

Pada pilihan How To Use akan menampilkan petunjuk informasi bagaimana cara penggunaan aplikasi. 


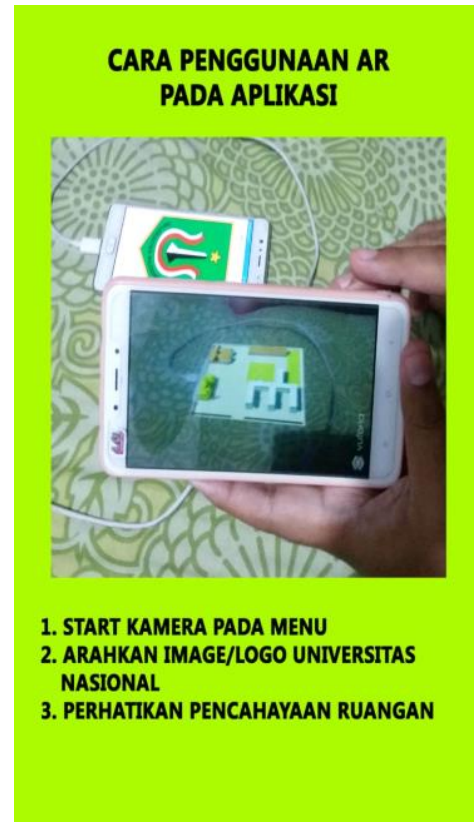

Gambar 10. How To Use

6). About Unas

Pada pilihan About Unas menampilkan informasi singkat tentang Universitas Nasional, dan terdapat nama website pada Universitas Nasional untuk mengetahui informasi lebih detail.

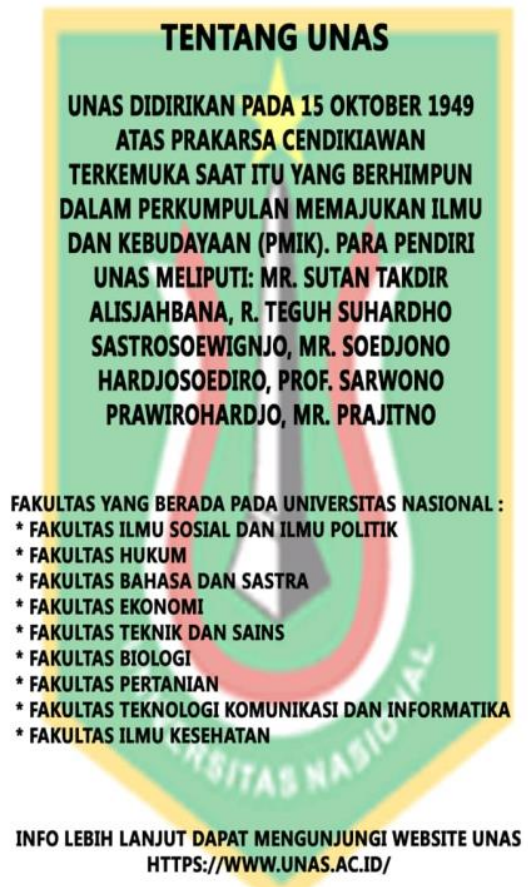

Gambar 11. About Unas

7). About Unas

Pada pilihan about application akan menampilkan informasi tentang aplikasi dan ARNAS dan tujuan dari aplikasi ARNAS dibuat.

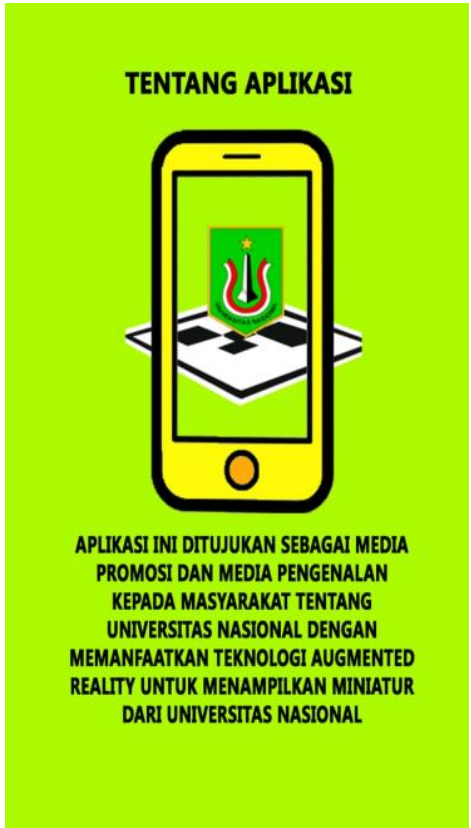

Gambar 12. About Application

8). About Development

Pilihan About Development menampilkan informasi profil singkat tentang pengembang aplikasi.

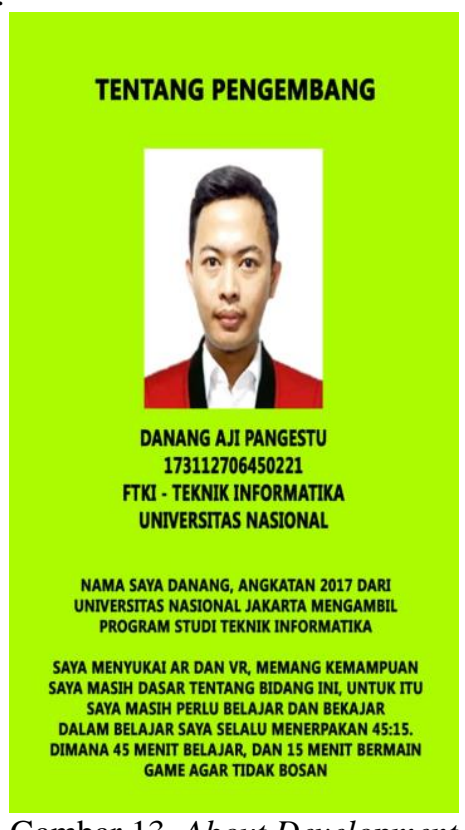

Gambar 13. About Development

\section{Pengujian Aplikasi}

Pada aplikasi ARNAS dilakukan dua pengujian aplikasi, antara lain dari versi android dan kamera. Pengujian dilakukan dengan tiga buah smartphone android dengan versi android yang berbeda.

Tabel 3. Perangkat Pengujian

\begin{tabular}{|l|l|}
\hline \multicolumn{1}{|c|}{ Perangkat } & \multicolumn{1}{c|}{ Versi Android } \\
\hline Oppo A37F & 5.1 .1 (Lolipop) \\
\hline Nubia M2 & 6.0 (Marshmallow) \\
\hline Vivo 1807 & 7.1 (Nougat) \\
\hline
\end{tabular}


1. Pengujian terhadap jarak

Pengujian berdasarkan jarak dilakukan berdasarkan jarak tertentu kamera pada perangkat dapat mendeteksi objek. Pengujian dilakukan dengan jarak minimum $10 \mathrm{~cm}$.

Tabel 4. Penujian marker membaca objek terhadap jarak $10 \mathrm{~cm}$

\begin{tabular}{|c|c|c|}
\hline Jarak & Versi Android & Keterangan \\
\hline \multirow{3}{*}{$10 \mathrm{~cm}$} & 5.1 .1 (Lolipop) & Terlihat \\
\cline { 2 - 3 } & 6.0 (Marshmallow) & Terlihat \\
\cline { 2 - 3 } & 7.1 (Nougat) & Terlihat \\
\hline
\end{tabular}

Tabel 5. Penujian marker membaca objek terhadap jarak $20 \mathrm{~cm}$

\begin{tabular}{|c|c|c|}
\hline Jarak & Versi Android & Keterangan \\
\hline \multirow{3}{*}{$20 \mathrm{~cm}$} & 5.1 .1 (Lolipop) & Terlihat \\
\cline { 2 - 3 } & 6.0 (Marshmallow) & Terlihat \\
\cline { 2 - 3 } & 7.1 (Nougat) & Terlihat \\
\hline
\end{tabular}

Tabel 6. Penujian marker membaca objek terhadap jarak $30 \mathrm{~cm}$

\begin{tabular}{|c|c|c|}
\hline Jarak & Versi Android & Keterangan \\
\hline \multirow{3}{*}{$30 \mathrm{~cm}$} & 5.1 .1 (Lolipop) & Tidak Terlihat \\
\cline { 2 - 3 } & 6.0 (Marshmallow) & Terlihat \\
\cline { 2 - 3 } & 7.1 (Nougat) & Terlihat \\
\hline
\end{tabular}

Tabel 7. Penujian marker membaca objek terhadap jarak $40 \mathrm{~cm}$

\begin{tabular}{|c|c|c|}
\hline Jarak & Versi Android & Keterangan \\
\hline \multirow{3}{*}{$40 \mathrm{~cm}$} & 5.1 .1 (Lolipop) & Tidak Terlihat \\
\cline { 2 - 3 } & 6.0 (Marshmallow) & Tidak Terlihat \\
\cline { 2 - 3 } & 7.1 (Nougat) & Terlihat \\
\hline
\end{tabular}

Tabel 8. Penujian marker membaca objek terhadap jarak $50 \mathrm{~cm}$

\begin{tabular}{|c|c|c|}
\hline Jarak & Versi Android & Keterangan \\
\hline \multirow{3}{*}{$50 \mathrm{~cm}$} & 5.1 .1 (Lolipop) & Tidak Terlihat \\
\cline { 2 - 3 } & 6.0 (Marshmallow) & Tidak Terlihat \\
\cline { 2 - 3 } & 7.1 (Nougat) & Tidak Terlihat \\
\hline
\end{tabular}

2. Pengujian terhadap sudut kemiringan

Pengujian terdadap sudut kemiringan dilakukan berdasarkan kemiringan tertentu kamera pada perangkat dapat mendeteksi objek. Pengujian dilakukan dengan sudut kemiringan maksimum $90^{\circ}$.

Tabel 9. Penujian marker membaca objek pada android lolipop

\begin{tabular}{|c|c|c|}
\hline Versi Android & Kemiringan & Keterangan \\
\hline \multirow{4}{*}{5.1 .1 (Lolipop) } & $0^{\circ}$ & Tidak Terlihat \\
\cline { 2 - 3 } & $10^{\circ}$ & Tidak Terlihat \\
\cline { 2 - 3 } & $20^{\circ}$ & Tidak Terlihat \\
\cline { 2 - 3 } & $30^{\circ}$ & Terlihat \\
\cline { 2 - 3 } & $40^{\circ}$ & Terlihat \\
\cline { 2 - 3 } & $50^{\circ}$ & Terlihat \\
\cline { 2 - 3 } & $60^{\circ}$ & Terlihat \\
\cline { 2 - 3 } & $70^{\circ}$ & Terlihat \\
\cline { 2 - 3 } & $80^{\circ}$ & Tidak Terlihat \\
\cline { 2 - 3 } & $90^{\circ}$ & Tidak Terlihat \\
\hline
\end{tabular}

Tabel 10. Penujian marker membaca objek pada android marshmallow

\begin{tabular}{|c|c|c|}
\hline Versi Android & Kemiringan & Keterangan \\
\hline \multirow{4}{*}{6.0 (Marshmallow) } & $0^{\circ}$ & Tidak Terlihat \\
\cline { 2 - 3 } & $10^{\circ}$ & Tidak Terlihat \\
\cline { 2 - 3 } & $20^{\circ}$ & Terlihat \\
\cline { 2 - 3 } & $30^{\circ}$ & Terlihat \\
\cline { 2 - 3 } & $40^{\circ}$ & Terlihat \\
\cline { 2 - 3 } & $50^{\circ}$ & Terlihat \\
\cline { 2 - 3 } & $60^{\circ}$ & Terlihat \\
\cline { 2 - 3 } & $70^{\circ}$ & Terlihat \\
\cline { 2 - 3 } & $80^{\circ}$ & Tidak Terlihat \\
\hline
\end{tabular}

Tabel 11. Penujian marker membaca objek pada android nougat

\begin{tabular}{|c|c|c|}
\hline Versi Android & Kemiringan & Keterangan \\
\hline \multirow{4}{*}{7.1 (Nougat) } & $0^{\circ}$ & Tidak Terlihat \\
\cline { 2 - 3 } & $10^{\circ}$ & Tidak Terlihat \\
\cline { 2 - 3 } & $20^{\circ}$ & Tidak Terlihat \\
\cline { 2 - 3 } & $30^{\circ}$ & Terlihat \\
\cline { 2 - 3 } & $40^{\circ}$ & Terlihat \\
\cline { 2 - 3 } & $50^{\circ}$ & Terlihat \\
\cline { 2 - 3 } & $60^{\circ}$ & Terlihat \\
\cline { 2 - 3 } & $70^{\circ}$ & Terlihat \\
\cline { 2 - 3 } & $80^{\circ}$ & Terlihat \\
\cline { 2 - 3 } & $90^{\circ}$ & Tidak Terlihat \\
\hline
\end{tabular}

\section{KESIMPULAN}

Berdasarkan penelitian yang telah dilaksanakan, maka dapat disimpulkan:

1. Aplikasi ARNAS (Augmented reality Universitas Nasional) dirancang sebagai media pengenalan serta promosi pada Universitas Nasional menggunakan augmented reality dengan metode marker based tracking. Marker yang digunakan untuk memunculkan objek adalah logo dari Universitas Nasional.

2. Pengujian aplikasi dilakukan dengan 2 cara, dari jarak kamera dan sudut kemiringan. Jarak minimum yang dilakukan pengujian adalah $10 \mathrm{~cm}$, dan pada jarak $50 \mathrm{~cm}$ objek tidak dapat terdeteksi. Pada sudut kemiringan, rata-rata objek dapat terbaca pada kemiringan $30^{\circ}$ sampai $70^{\circ}$.

3. Aplikasi dibangun menggunakan software game engine Unity3D dengan Vuforia SDK. Aplikasi ARNAS dapat berjalan pada platform android.

\section{DAFTAR PUSTAKA}

[1] A. D. Rachmanto and M. S. Noval, "Implementasi Augmented Reality Sebagai Media Pengenalan Promosi Universitas Nurtanio Bandung Menggunakan Unity 3D," Implementasi Augment. Real. Sebagai Media Pengenalan Promosi Univ. Nurtanio Bandung Menggunakan Unity 3D, vol. IX, no. 1, pp. 29-37, 2018.

[2] T. Sifana, A. Rismayanti, and T. F. Prasetyo, "Penerapan Teknologi Augmented Reality sebagai Media Pengenalan Kampus Berbasis Android dengan Menggunakan Metode Multimedia Development Life Cycle,” pp. 82-88, 
2015.

[3] A. Reality et al., "Augemented Reality Media Pendukung... (Yudhistira dkk.)," pp. 140-145, 2015.

[4] J. Grafika and N. Yogyakarta, "Prosiding SNST ke-6 Tahun 2015 Fakultas Teknik Universitas Wahid Hasyim Semarang 207," pp. 207-215, 2015.

[5] D. Suhenra, M. Ahyar, and M. M. Parenreng, "Penerapan Augmented Reality sebagai Media Pengenalan Kampus Politeknik Negeri Ujung Pandang," Semin. Nas. Tek. Elektro dan Inform., no. September, pp. 177-276, 2018.

[6] K. Sawant, "Introduction to Augmented Reality: An overview , Development of AR in Android," Int. J. Adv. Res. Comput. Eng. Technol., vol. 5, no. 6, pp. 1989-1994, 2016.

[7] J. Edward, "AUGMENTED REALITY VISUALISASI LINGKUNGAN KAMPUS POLITEKNIK NEGERI BATAM Augmented Reality Visualisasi Lingkungan Kampus Politeknik Negeri Batam Menggunakan Metode Single Marker," 2015.

[8] M. Widyaningsih and M. I. Y. Zunfikar, "As Media Augmented Reality Promotion of College with Marker Logo in Brochure," Int. J. Sci. Res. Manag., vol. 05, no. 09, 2017, doi: 10.18535/ijsrm/v5i9.15.

[9] S. S. Wicida, "Berbasis Augmented Reality Pada Brosur," pp. 7-11.

[10] D. Kim, W. Ryu, S. Lee, B. Lim, and S. Lee, "A Unity3D-based mobile fashion coordination system," Int. J. Adv. Media Commun., vol. 6, no. 1, pp. $\quad 86-92, \quad 2016, \quad$ doi: 10.1504/IJAMC.2016.079110.

[11] E. Y. Daraghmi, "Augmented Reality Based Mobile App for a University Campus," vol. 5, pp. 153-167, 2017.

[12] T. W. Ginting, V. Tulenan, and H. Wowor, "Pengenalan Gedung Kampus Universitas Sam Ratulangi Dengan Pemanfaatan Augmented Reality Dan Layanan Berbasis Lokasi," J. Tek. Inform., vol. 9, no. 1, 2016, doi: 10.35793/jti.9.1.2016.13754. 